\title{
THE
}

\section{The Quality Movement in Hospital Care}

Jeffrey E. Jarrett

University of Rhode Island, jejarrett133@outlook.com

Follow this and additional works at: https://digitalcommons.uri.edu/cba_facpubs

The University of Rhode Island Faculty have made this article openly available.

Please let us know how Open Access to this research benefits you.

This is a pre-publication author manuscript of the final, published article.

Terms of Use

This article is made available under the terms and conditions applicable towards Open Access Policy Articles, as set forth in our Terms of Use.

\section{Citation/Publisher Attribution}

Jarrett, Jeffrey E. (2013) The Quality Movement in Hospital Care. Quality and Quantity, November 2013. Available at http://link.springer.com/article/10.1007/s11135-013-9947-9.

This Article is brought to you for free and open access by the College of Business at DigitalCommons@URI. It has been accepted for inclusion in College of Business Faculty Publications by an authorized administrator of DigitalCommons@URI.For more information, please contact digitalcommons-group@uri.edu. 


\section{Quality \& Quantity \\ The Quality Movement in Hospital Care \\ --Manuscript Draft--}

Manuscript Number:

Full Title:

Article Type:

Keywords:

Corresponding Author:
QUQU-D-13-00452

The Quality Movement in Hospital Care

Original paper

Key Terms:

Statistical Process Control (SPC)

Hospital Care

Multivariate Quality Control

Auto correlated time series

Average Run Length (ARL)

Causes of Variation

Common and Special Causes

Jeffrey E Jarrett, Ph.D.

UNITED STATES

\section{Corresponding Author Secondary}

Information:

Corresponding Author's Institution:

Corresponding Author's Secondary Institution:

First Author:

Jeffrey E Jarrett, Ph.D.

First Author Secondary Information:

Order of Authors:

Jeffrey E Jarrett, Ph.D.

Order of Authors Secondary Information:

\begin{tabular}{|l|l|}
\hline Abstract: & $\begin{array}{l}\text { Abstract } \\
\text { The purpose is to introduce the demand for the quality movement practice in hospital } \\
\text { care. We show both the need and application of quality monitoring, especially the } \\
\text { need monitoring activities having auto correlated data flows of which there are many in } \\
\text { the hospital environment. The goal is to control the flow of quality care data in the } \\
\text { dynamic behavior of these systems of acre in hospitals. These monitoring systems are } \\
\text { designed to control and improve changes in the hospital care environment. }\end{array}$ \\
\hline Suggested Reviewers: & $\begin{array}{l}\text { David West, Ph.D. } \\
\text { Professor, Eat Carolina University } \\
\text { WESTD@ecu.edu } \\
\text { He has the bacgound in educatin and publications to review this manuscript. }\end{array}$ \\
\hline
\end{tabular}




\section{The Quality Movement in Hospital Care}

(September, 2013)

Jeffrey E. Jarrett, Ph.D.

Professor, Management Science

University of Rhode Island

jejarrett@mail.uri.edu 


\begin{abstract}
The purpose is to introduce the demand for the quality movement practice in hospital care.

.We show both the need and application of quality monitoring, especially the need monitoring activities having auto correlated data flows of which there are many in the hospital environment. The goal is to control the flow of quality care data in the dynamic behavior of these systems of acre in hospitals. These monitoring systems are designed to control and improve changes in the hospital care environment.
\end{abstract}

\title{
Key Terms:
}

Statistical Process Control (SPC)

Hospital Care

Multivariate Quality Control

Auto correlated time series

Average Run Length (ARL)

Causes of Variation

Common and Special Causes 


\section{Introduction}

Statistical Quality Control or monitoring of systems collecting data on hospital care is not new to analyzers of Total Quality Management programs. TQM is no longer a new term in hospital care but has definitions varying from the management of care to stronger applied statistical systems analysis. Quality management which includes statistical quality control (SQC) designed to involve the leveraging of channel wide integration to better serve customer or patient needs results in increases in productivity and the improvement in quality of care. These improvements follow when Hospital management health managers implement and coordinate quality management activities upstream. Hospital management must recognize anew two duties to be undertaken. First, I refer to the process whereby measures are taken to make sure defects in services are not part of the final output, and that the output meets quality and acceptable health standards. Second, one may observe that quality assurance entails overlooking all aspects, including design, development, service, installation, as well as documentation. The Quality movement is the field that ensures that management maintains the standards set and continually improves the quality of the output. The quality movement [Lee and Wang (2003), Weihs and Jessenberger (1999)]] offers useful sound lessons that can be very powerful to address hospital care quality. Instead of final, end-service source inspection, the quality movement emphasizes prevention, integrated source inspection, process control and continuous improvement. These are all ingredients for successful and effective ways to manage and mitigate the risks in various health care settings. [See Woodall, (2005) and Papaioannon, et al. 2010a) and (2010b).]

If a hospital were to monitor the incidence characterized by the results of laboratory test on a similar fluid compound for the results on a special population of patients where the laboratory tests are done pm a period of time for example twenty weeks. The monitoring would require a series of tests to determine whether characteristics measured are caused by common causes or special causes of variation, the result would be control charts of individual observations and range control charts in the methods originally developed by "Shewhart" in his known works on industrial applications. In turn, others, 1.e., Griggs and Spiegalhalter (2007) that in tests that are combined estimation and tested by standard statistical testing of "no change." In addition, they suggested the use of exponentially weighted moving average (EWMA) control charts to solve the problems associated with 
hospital monitoring of laboratory test results and similar problems. In the next section, information and research is presented that this solution will fail when laboratory results contain much more information than analyzed by EWMA and simpler models.

\section{Evidence from Previous Research}

We introduce the philosophy and methods of the quality improvement to achieve the best results of hospital operations. This paper focuses on service operations with quality control in an environment with multiple service centers and multiple customers. We first discuss the need for quality planning in the hospital environment vital to the performance of health programs, specific needs of patients and patient community and to focus on where the notion of SPC fits and why it is so vital to the performance of hospital care global health environment of the patient population. In turn, we introduce and discuss the desire for more sophisticated methods to insure that quality and improvement is maintained in health processes including treatment systems to cleanse the hospital and provider of care facilities.

While provider of care programs are so crucial to the general health of society, these health systems must be sustained by both preventative and emergency measures. Zhang, Yu and Huang (2009) propose several sophisticated strategies for dealing with SPC strategies in an environment where service flows continue over time. Their study presents principle agent models regarding the consumer's quality evaluation and the supplier's quality prevention level decisions. Studies such as this may produce results not heretofore examined by the practioner's of SPC in provider of care programs. In addition, threats to water quality within provider of care facilities are real and many and measures must be developed to indicate when water quality and similar processes are not operating in an efficient and productive manner. These measures include those of SPC which will indicate when risks are present in the inspection processes in provider of care facilities. Since providers of care have serious supply chain problems, (i.e. blood supplies and access to programs which bring in life-saving drug supplies, equipment and personnel) are increasingly globalized. SPC tools and measures must be strategically incorporated into inspection and monitoring programs and the choice of the particular SPC procedures are critical in developing of optimal plans. The choice of an emergency care provider is crucial in the saving of lives and rehabilitation.

Most SPC methodologies assume a steady state process behavior where the influence of dynamic behavior either does not exist or is ignored. The focus is on the control of only one variable at a time and distinguishes between Phases I [analysis of historical data] and II [monitoring quality levels]. Specifically, SPC controls for changes in either the measure of location or dispersion or both. SPC procedures as practiced in each phase may disturb the flow of the service production process and operations. In recent years, the use of SPC methodologies to address the process where behavior is characterized by more than one variable is emerging. The purpose of this next section is to review the basic Univariate procedures to observe how one improves the performance of SPC to achieve better measures in Phase II by considering average run length performance (ARL). 


\section{Univariate (Shewhart) Control Charts}

A Shewhart control chart which is the central foundation of univariate (singe variable) SPC has one major shortcoming. This control chart is considers only the last data point and does not carry a memory of the previous data. As a result, small changes in the mean of a random variable are not likely to be detected rapidly. As noted by Griggs and Spiegelhalter (2007), exponentially weighted moving average (EWMA) charts improve upon the detection of small process shifts. Rapid detection of relatively small changes in the quality characteristic of interest and ease of computations through recursive equations are some of the many good properties of the EWMA chart that make it attractive.

EWMA chart achieves faster detection of small changes in the mean. The EWMA chart is used extensively in time series modeling and forecasting for processes with gradual drift (Box and Draper, 1998). EWMA provides a forecast of where the process will be in the next instance of time. It thus provides a mechanism for dynamic process control (Hunter, 1986). Later, examples of these methods will be analyzed.

The EWMA is a statistic for monitoring the process that averages the data in a way that gives exponentially less and less weight to data as they are further removed in time. The procedures for developing EWMA control charts give details on implementing this type of Phase I system. [Montgomery (2013) contains the development of the models for finding the control limits in this for the univariate charts and need not be discussed further at this point.]

In many situations, the sample size used for process control is $n=1$; that is the sample consists of an individual unit [Montgomery and Runger, (2003)]. In such a situation, the individuals control chart is used. The control chart for individuals uses the moving range of two successive observations to estimate the process variability. Such small samples may lead to false signals which increase the likelihood of Type II errors, i.e., the error of leaving a process alone when it should be stopped and a search for the malfunctions should be implemented. Provider of care $h$ ealth models were further explored in detail by

Often, in provider of care treatment programs, the distinction between Phases I and II is not clear. Sonesson and Bock (2003) pointed out problems and issues related to statistically based evaluations. Researchers, often, did not examine average run length (ARL) of a proposed method over a variety of alternative process shifts. ARL performance of a proposed method or program for an in-control state and for a single shift in the service process for which the proposed detection program optimizes must be evaluated. If the system is not optimized, misplaced control limits may result. The system for detection of quality shifts is sub-optimized and better techniques should be sought. In the next section, we introduce methods and their possible use in processes having dynamic inputs [Yeh and Hwang, (2004)].

Alwan (1992) found that more than $85 \%$ of process control applications studied resulted in charts with possibly misplaced control limits. In many instances, the misplaced control limits result from the autocorrelation of the process observations, which violates a basic assumption often associated with the Shewhart chart (Woodall (2000)). Autocorrelation of process observations has been reported in many industries, including cast steel (Alwan (1992), wastewater treatment plants (Berthouex, Hunter, and Pallesen (1978)), chemical processes industries (Montgomery and Mastrangelo (1991) and many other service industries and programs. Several models have been proposed to monitor processes with auto correlated observations. Alwan and Roberts (1988) suggest using an autoregressive integrated moving average (ARIMA) residuals chart, which they 
referred to as a special cause chart. For subsample control applications, Alwan and Radson (1992) describe a fixed limit control chart, where the original observations are plotted with control limit distances determined by the variance of the subsample mean series. Montgomery and Mastrangelo (1991) use an adaptive exponentially weighted moving average (EWMA) centerline approach, where the control limits are adaptive in nature and determined by smoothed estimate process variability. Lu and Reynolds (1999) investigate the steady state ARL of cumulative sum (CUSUM), EWMA, and Shewhart control charts for auto correlated data modeled as a first order autoregressive process plus an additional random error term. Last, Box and Luceno (1997) considering quality monitoring by feedback adjustment from additional laboratory test and hospital information.

A problem with all these control models is that the estimate of the process variance is sensitive to outliers. If assignable causes are present in the data used to fit the model, the model may be incorrectly identified and the estimators of model parameters may be biased, resulting in loose or invalid control limits (Boyles (2000)). To justify the use of these methods, researchers have made the assumption that a period of "clean data" exists to estimate control limits. Therefore, methods are needed to assure that parameter estimates are free of contamination from assignable causes of variation. Intervention analysis, with an iterative identification of outliers, has been proposed for this purpose. The reader interested in more detail should see Alwan (2000, pp 301-307), Atienza, Tang and Ang (1998), and Box, Jenkins, and Reinsel (1994, pp. 473-474 and 2008). Atienza, Tang, and Ang (1998) recommend the use of a control procedure based on an intervention test statistic, $\lambda$, and show that their procedure is more sensitive than ARIMA residual charts for process applications with high levels of positive autocorrelation. They limit their investigation of intervention analysis, however, to the detection of a single level disturbance in a process with high levels of first order autocorrelation. Wright, Booth, and Hu (2001) propose a joint estimation method capable of detecting outliers in an auto correlated process where the data available is limited to as few as 9 to 25 process observations. Since intervention analysis is crucial to model identification and estimation, we investigate varying levels of autocorrelation, autoregressive and moving average processes, different types of disturbances, and multiple process disturbances.

The ARIMA and intervention models are appropriate for auto correlated processes whose input streams are closely controlled. However, there are quality applications, which we refer to as "dynamic input processes," where this is not a valid assumption. The treatment of wastewater is one example of a dynamic process that must accommodate highly fluctuating input conditions. In the health care sector, the modeling of emergency room service must also deal with highly variable inputs. The dynamic nature of the input creates an additional source of variability in the system, namely the time series structure of the process input. For these applications, modeling the dynamic relationship between process inputs and outputs can be used to obtain improved process monitoring and control as discussed by Alwan (2000, pp. 675-679). West, Delana and Jarrett (2002) proposed the following transfer function model to solve problems having dynamic behavior. If a process quality characteristic that is a variable has a time series structure, one can estimate an ARIMA model which represents the undisturbed or natural process variation.

Although this model is an improvement over EWMA and similar models, it does not consider that variable over time may be correlated with other variables in the same process. For example, these processes introduced originally by Chen and Liu (1993a, 1993b). If the time series is contaminated by periods of external disturbances to the process, the ARIMA model may be incorrectly specified, the variability of the residuals overestimated, and the resulting control limits incorrectly placed. 
By following the transfer function model of Box and Tiao (1975), West, Delana and Jarrett (2002) described the observed quality characteristic as a function of three time series which included the notion of intervention analysis. The intervention analysis represents a special cause of variation. However, this methodology requires additional research to be implemented by standard quality control software such as Minitab ${ }^{\circledR}$ and $S A S \circledR$. Future research will determine in its usefulness in service operations such as the provision of health care. Last, Box, Jenkins and Reinsel (1994, p 392, or 2008) for the development of the transfer function term, and Box, Jenkins and Reinsel (1994, p 462, or 2008) for details of the intervention term. The rational coefficient term if It is a ratio of polynomials that defines the nature of the disturbance as detailed in Box, Jenkins and Reinsel (1994, p 464, or 2008). The third term is the basic ARIMA model of the undisturbed process. Different types of disturbances can be modeled by the proper design of the intervention term. The two most common disturbances for quality applications are a point disturbance, with an impact observed for only a single time period, and a step disturbance, with an impact persisting undiminished through several subsequent observations. The point disturbance is modeled as an additive outlier (AO). An AO impacts the observed process at one observation which is a constant. A step disturbance term introduced by Chang, Tiao, and Chen (1988) and Chen and Liu (1993a, 1993b) where they discuss both types of disturbances.

Chang, Tiao, and Chen (1988) extended the concepts of Box and Tiao (1975) to an iterative method for detecting the location and nature of outliers at unknown points in the time series. The above researchers defined procedures for detecting innovational outliers and additive outliers and for jointly estimating time series parameters. Their work also demonstrates the need for future study of the nature of outliers.

\section{Multivariate Quality Control (MQC)}

Multivariate analyses utilize the additional information due to the relationships among the variables and these concepts may be used to develop more efficient control charts than simultaneously operated several univariate control charts. The most popular multivariate SPC charts are the Hoteling's T2 (see Sullivan and Woodall (1996) and multivariate exponentially weighted moving average (MEWMA) (Elsayed and Zhang, 2007). Multivariate control chart for process mean is based heavily upon Hotelling's T2 distribution, which was introduced by Hotelling (1947). Other approaches, such as a control elipse for two related variables and the method of principal components, are introduced by Jackson (1956) and Jackson. A straightforward multivariate extension of the univariate EWMA control chart was first introduced in Lowry Woodall, Champ and Rigdon (1992) and Lowry and Montgomery developed a multivariate EWMA (MEWMA) control chart. It is an extension to the univariate EWMA. Multivariate quality control (MPC) charts (Hotelling, 1947, Jackson, 1956, 1959 and 1985, Hawkins, 1991, and 1993, Kalagonda and Kulkarni, 2003 and 2004, Wierda, 1994, and Jarrett and Pan, 2006, 2007a and 2007b, Mestik, Mastrangelo and Forrest, 2002) have several advantages over creating multiple Univariate charts for the same business situation:

1. The actual control region of the related variables is represented. In the bivariate case the representation is elliptical.

2. You can maintain a specific probability of a Type 1 error (the risk). 
3. The determination of whether the process is out of or in control is a single control limit.

Currently, there is a gap between theory and practice and this is the subject of this manuscript. Many practitioners and decision-makers have difficulty interpreting multivariate process control applications although the book by Montgomery (2013) addresses many of the problems of understanding not discussed in the technical literature noted before. For example, the scale on multivariate charts is unrelated to the scale of any of the variables, and an out-of-control signal does not reveal which variable (or combination of variables causes the signal).

Often one determines whether to use a univariate or multivariate chart by constructing and interpreting a correlation matrix of the pertinent variables. If the correlation coefficients are greater than 0.1 , you can assume the variables correlate, and it is appropriate to construct a multivariate quality control chart.

The development of information technology enables the collection of large-size data bases with high dimensions and short sampling time intervals at low cost. Computational complexity is now relatively simple for on-line computer-aided processes. In turn, monitoring results by automatic procedures produces a new focus for quality management. The new focus is on fitting the new environment. SPC now requires methods to monitor multivariate and serially correlated processes existing in many time series of provider of care treatment programs. SPC emphasizes the properties of control for decision making while it ignores the complex issues of process parameter estimation. Estimation is less important for Shewhart control charts for serially independent processes because the effects of different estimators of process parameters are nearly indifferent to the criterion of ARL. Processes' having serial correlation, estimation becomes the key to correct construction of control charts' :

1. The actual control region of the related variables is represented. In the bivariate case the representation is elliptical.

2. You can maintain a specific probability of a Type 1 error (the risk).

3. The determination of whether the process is out of or in control is a single control limit.

Currently, there is a gap between theory and practice and this is the subject of this manuscript. Many practitioners and decision-makers have difficulty interpreting multivariate process control applications although the book by Montgomery (2013) addresses many of the problems of understanding not discussed in the technical literature noted before. For example, the scale on multivariate charts is unrelated to the scale of any of the variables, and an out-of-control signal does not reveal which variable (or combination of variables causes the signal). Often one determines whether to use a univariate or multivariate chart by constructing and interpreting a correlation matrix of the pertinent 
variables. If the correlation coefficients are greater than 0.1 , you can assume the variables correlate, and it is appropriate to construct a multivariate quality control chart.

The development of information technology enables the collection of large-size data bases with high dimensions and short sampling time intervals at low cost. Computational complexity is now relatively simple for on-line computer-aided processes. In turn, monitoring results by automatic procedures produces a new focus for quality management. The new focus is on fitting the new environment. SPC now requires methods to monitor multivariate and serially correlated processes existing in many time series of provider of care treatment programs.

SPC emphasizes the properties of control for decision making while it ignores the complex issues of process parameter estimation. Estimation is less important for Shewhart control charts for serially independent processes because the effects of different estimators of process parameters are nearly indifferent to the criterion of ARL. Processes' having serial correlation, estimation becomes the key to correct construction of control charts. Adopting workable estimators is then an important issue.

In the past, researchers studied SPC for serially correlated processes and SPC for multivariate processes separately. Research on quality control charts for correlated processes focused on Univariate processes. Box, Jenkins, and Macgregor (1974) and Berthouex, Hunter and Pallesen (1978) noticed and discussed the correlated observations in production processes. Alwan and Roberts (1988) proposed a general approach to monitor residuals of Univariate auto correlated time series where the systematic patterns are filtered out and the special changes are more exposed. Other studies include Montgomery and Friedman (1989), Harris and Ross (1991), Montgomery and Mastrangelo (1991), Maragah and Woodall (1992), Wardell, Moskowitz and Plante (1994), Lu and Reynolds (1999), West, Delana and Jarrett (2002) and West and Jarrett (2004), English and Sastri (1990), Pan and Jarrett (2004) suggested state space methodology for the control of auto correlated process. Further, additional technologies implemented by Testik (2005), Yang and Rahim (2005) and Yeh, Huang and Wu (2004) provide newer methods for enabling better MPC methods.

In Alwan and Roberts' approach, a time series is separated into two parts that are monitored in two charts. One is the common-cause chart and the other is the special-cause chart. The common cause chart essentially accounts for the process's systematic variation that is represented by an autoregressive-integrated-moving-average (ARIMA) model, while the special cause chart is for detecting assignable causes that can be assigned in the residual of the ARIMA model. That is, the special cause chart is designed as Shewhart-type chart to monitor the residuals filtered and whitened from the auto correlated process (with 
certain or estimated parameters). In this analysis, the authors suggest methods used in conventional quality control software (i.e., Minitab) entitled multivariate $\mathrm{T}^{2}$ and Generalized Variance control charts. These multivariate charts show how several variables jointly influence a process or outcome. For example, you can use multivariate control charts to investigate how the tensile strength and diameter of a fiber affect the quality of fabric or any similar application. If the data include correlated variables, the use of separate control charts is misleading because the variables jointly affect the process. If you use separate univariate control charts in a multivariate situation, Type I error and the probability of a point correctly plotting in control are not equal to their expected values. The distortion of these values increases with the number of measurement variables. In the next section, we will consider an illustration which is an example of the use of univariate control charts with one observation per time period. Since the observation is an individual with three variables and we will utilize the appropriate control chart.

\section{An Example of Quality Control in a Provider of Care (i.e. an acute care hospital)}

We begin by collecting data in an emergency facility whereby a series of tests produce data on three factors. Over a period of twenty days, one collects and processes the data by a simple Univariate Control Chart for each variable. In turn, the quality analyst plots the variables on separate to determine whether special causes of variation are present.

The illustration begins by the quality analysts collecting data in an emergency facility whereby a series of tests produce data on three factors. Over a period of twenty days, the analysts collects and processes the data by a simple Univariate Control Chart for each variable. In turn, the quality s analyst plots the variable on separate control charts to determine whether special causes of variation are present.

Assume the facility is a leader in providing care for patients with special needs, the Hospital provides clinical, therapeutic, and educational programs for patients with a variety of disabilities. The hospital staff promotes the integrity and well-being of patients through the high quality of care and a commitment to helping each patient reach his or her full potential. When it comes to the quality of care patients receive, the hospital's personnel fosters continuous improvement to improve all facets of care from reducing patient waiting room times to boosting the efficiency of operating rooms. With the help of Lean Six Sigma and quality control software, this provider of care hospital is able to analyze information about its processes and make real-time decisions that increase the efficiency of providing technical information to physicians and surgeons and enabling them to see additional patients. Twenty samples collected and processed though hospital laboratory equipment are in turn analyzed by Univariate "I-MR" control charts for mean and variation. Points out 
of control are than evaluated by attending physicians and surgeons. The results are presented for each of the three variables in Figure 1, a, b, and c.

--Insert Figure 1(a) about here--

As noted in the figure 1 , the point out of control are 1 and 5 in the Individuals (I) control chart and points $\mathbf{5}$ and $\mathbf{6}$ in the Moving-Range (MR) for the variable Impurities. From the control chart we see there is correspondence at point 5 but the two charts are not in concordance for the other sample points. The lack of concordance is not unusual for I-MR control charts and Pan and Jarrett (2013) suggest one solution using an application of the golden ratio. This solution provides a solution the problem of finding conflicting signals in mean and variation charts. However, the solution does not consider I-MR control charts as we have in our illustration.

Insert Figure $1(\mathrm{~b})$ about here

For the variable concentration ratio, we observe two points are out of control, $\mathbf{1 9}$ and $\mathbf{2 0}$ in the I control chart. For the MR control chart there are no points out of control.

Insert Figure 1(c) about here

For the variable temperature (Celsius), we observe no points out of control on the I control chart but point $\mathbf{1 6}$ is out of control on the MR control chart for variation. Again, we have no concordance on the two control charts. In the next section, we attempt to improve the results by including a factor to account for the dynamic factor that exists in data observations over time. This solution using the exponentially weighted moving-average (EWMA) model in the determining of control limits.

\section{EWMA Control Chart Analysis}

EWMA control charts are useful because they include a factor for dynamic activity in the variables that are of interest by analysts in the acute care (hospital) environment. The EWMA will detect small changes in a process not detected by simpler control charts. This should be noted since the Shewhart control charts have no provision to detect the dynamic changes that are not small. Figures 2 ( $a, b$ and $c$ ) provide the results of using EWMA methodology using the same data of the previous illustration.

For the variable impurities, Figure 2 (a) indicates that one point (1) is out of control. Note also, that trend in the values of the observations changes dramatically at this point. First, the observations tend to decline over time and after point 15 , the observations tend to change direction at point 5 and 15 indicating that probably significant changes in the dynamic behavior of the data occurred at these points. In the last six sample observation 
were increasing, there is a strong possibility that the sample observations above 20 may be greater than the UCL. At that time, this variable will be out of control again.

Insert Figure 2(a) about here

For the variable concentration ratio, we observe in Figure 2(b) to points are out of control at the two last observations, $\mathbf{1 9}$ and $\mathbf{2 0}$. These points are above the UCL and appear at the end of a substantial upward trend in the data.

Insert Figure 2(b) about here

Last, the third variable, The EWMA control chart indicates that one point, 15, is out of control. Note also, that trend in the values of the observations changes dramatically at this point. First, the observations tend to decline over time and after point 15, the observations tend to change direction and increase from observation to observation. Unless, the second (increasing) trend ceases, the chart should indicate points above the upper control limit (UCL) will appear.

Insert Figure 2(c) about here

\section{Multivariate Control Chart Analysis}

Now, we employ MPC which utilizes the correlation among the three variables in the solution being observed. As noted above the MPC charts uses average run length as the measure for judging whether the process is in-control or out-of-control. Again there is only one chart for the three variables and one need to study Montgomery (2013) for the mathematical structure of the control charts. Using Hotelling's $\mathrm{T}^{2}$ methods Figure 3a details the results. The LCL is zero, the median is 4.03 and the UCL is 14.69. Observe that the spread of the data is not according to a normal (bell-shaped) model, but contains skewness in the upward direction. Points $\mathbf{1 , 1 9}$ and $\mathbf{2 0}$ are out of control and two are at the end of sampling in terms of time. The data under the MPC control chart indicates the $\boldsymbol{p}$-value for statistical tests. For example if the hospital data, the test results indicate that point 1 exceeds the upper control limit. The $p$-values for the decomposed $T$ statistic indicate that both impurities $(0.0021)$ and concentration ratio $(0.0039)$ contribute significantly to this out-of-control point. We make similar conclusions for points 19 and 20 at the $p$-values indicated in the data of Figure 3a.

To sum up, the multivariate method contains a simpler result to understand than some of the lack of concordance noted in the Univariate control charts and the notion that the correlation of the three variables are zero in both the Univariate and EWMA control chart 
analysis. The variables cross-correlation is also exhibited by the Hotelling's $\mathrm{T}^{2}$ MPC control chart.

Insert Figure 3(a) about here

In Figure 3b, we construct the generalized variance chart of all three variables. The generalized variance control chart determines whether or not the joint process variability for the three variables is in control. If the points lie outside the UCL and LCL than one concludes that there is evidence of unusual variation. Stated differently, the data may indicate special causes of variation. Since none of the observations (points) are out of control, we can conclude that there is no significant jount process variability

Insert Figure 3(b) about here

Last, a straightforward multivariate extension of the univariate EWMA control chart was first introduced in Lowry Woodall, Champ and Rigdon (1992) and Lowry and Montgomery developed a multivariate EWMA (MEWMA) control chart. It is an extension to the univariate EWMA. Multivariate quality control (MPC) charts (Hotelling, 1947, Jackson, 1956, 1959 and 1985, Hawkins, 1991, and 1993, Kalagonda and Kulkarni, 2003 and 2004, Wierda, 1994, and Jarrett and Pan, 2006, 2007a and 2007b, Mestik, Mastrangelo and Forrest, 2002) have several advantages over creating multiple Univariate charts for the same business situation. A straightforward multivariate extension of the univariate EWMA control chart was first introduced in Lowry Woodall, Champ and Rigdon (1992) and Lowry and Montgomery developed a multivariate EWMA (MEWMA) control chart. It is an extension to the univariate EWMA. This method is similar to MPC. Again this will improve results when data on variables contain both cross-correlation and auto correlation. Multivariate Time Methods (Transformation Analysis; Box, Jenkins and Reinsel, 2008)) may also prove useful in the future. This topic will be left future researchers.

\section{Conclusion}

Acute-care facilities (Hospitals and similar institutions) are among the many institutions that gather huge amounts of data on their clientele and at the same time determine programs of care to alleviate pain, reduce the effects of disease and, of course, save lives. Data must be quickly and properly analyzed before diagnoses are made and plans of care determined. Acute-care decision-makers must be able to understand the information provided by medical information statistical systems and data banks.

Total quality management in the acute care industry requires use of modern tools of quality control and improvement methods designed originally for industrial systems but spreading in its use in service operation. Supply chain management, retail store operations, production of high technology products, food science, and other others provide examples of industries in which control charts have proven to be exceptionally useful in determining 
high level of care in output. Acute-care facilities are no exception. They must implement the most appropriate tools for improving quality of care in their institution.

Our illustrations using test data indicate that MPC methods may provide much superior analysis for data that contains two or variables that are cross-correlated. SPC methods are more limited in scope which, in turn, leads to inappropriate conclusions and plans of care that not optimal. 


\section{References}

Alwan, B.M., and H.V. Roberts (1988) "Time-Series Modeling for Detecting Level Shifts of Auto correlated Processes", Journal of Business and Economics Statistics, 6, 87-96

Alwan, L.C. (2000) Statistical Process Analysis, Irwin-McGraw-Hill, New York, NY

Alwan, L.C. (1992) "Effects of Autocorrelation on Control Charts," Communication in Statistics-Theory and Methods, 21, 4, 1025-1049

Alwan, L.C. and D. Radson (1992) "Time-Series Investigation of Subsample Mean Charts," IIE Transactions, 24, 66-80

Atienza, O.O., Tang, L.C., and Ang, B.W. (1998) “A SPC Procedure for Detecting Level Shifts of Auto correlated Processes," Journal of Quality Technology, 30, 340-351

Benneyan, J.C., (2001) "Number-between g-type Statistical Quality Control Charts for Monitoring Adverse Events," Health Care Management Science, 4, 4, 305-318

Berthouex, P.M., Hunter, E. and Pallesen, L (1978), "Monitoring Sewage Treatment Plants: Some Quality Control Aspects”, Journal of Quality Technology, 10, 4, 139-149

Box, G. E. P., and Draper, N. R., (1987), Empirical Model Building and Response Surfaces, John Wiley \& Sons, New York, NY.

Box G.E.P., Jenkins, G.M. and Reinsel, G.C. (1994, and 2008) Time Series Analysis, Forecasting and Control, Prentice-Hall, Englewood Cliffs, NJ

Box, G.E.P. Jenkins, G.M. and Reinsel, G.C. (1994 and 2008) Time Series Analysis: Forecasting and Control 3rd and 4thed., Wiley, ISBN: 978-0-470-27284-8

Box, G.E.P. and Luceno, A. (1997) Statistical Control: By Monitoring and Feedback Adjustment Wiley-Interscience

Box, G.E., and Tiao, G.C. (1975) "Intervention Analysis with Applications to Economic and Environmental Problems," Journal of the American Statistical Association, 70, 70-79.

Chang, I, Tiao, G.C. and Chen, C. (1988) "Estimation of Time Series Parameters in the Presence of Outliers," Technometrics, 30, 193-204

Chen, C. and Liu, I., (1993a) "Joint Estimation of Model Parameters and Outlier Effects in Time Series," Journal of the American Statistical Association, 88, 284-297

Chen, C. and Liu, I., (1993b) "Forecasting Time Series with Outliers," Journal of Forecasting, 12, 13-35 
Boyles, R.A. (2000) "Phase I Analysis for Auto correlated Processes," Journal of Quality Technology, 32, 395-409

Elsayed, E. A. and Zhang, H., (2007) "Design of Optimum Simple Step-Stress Accelerated Life Testing Plans," Recent Advancement of Stochastic Operations Research, Edited by S., Dohi, T., S. Osaki and Sawaki, K., World Scientific, Singapore, January 2007

English, J.R. and Sastri, T. (1990) "Enhanced Quality Control in Continuous Flow Processes", Computers and Industrial Engineering, 19, 258-262

Griggs, O.A. and Spiegelhalter, D.J. (2007), “A Simple risk-adjusted exponentially weighted moving average, Journal of the American Statistical Association, 102,477, 140-152

Harris, T.J., and Ross, W.H. (1991), "Statistical Process Control Procedures for Correlated Observations", Canadian Journal of Chemical Engineering, 69, 48-57

Hawkins, D.M. (1991) "Multivariate Quality Control Based on Regression Adjusted for Variables”, Technometrics, 33, 1, 61-75

Hawkins, D.M. (1993) "Regression Adjustment for Variables in Multivariate Quality Control”, Journal of Quality Technology, 25, 3, 37-43

Hotelling, H. (1947) “Multivariate Quality Control”, Techniques of Statistical Analysis, Eisenhart, Hastay, and Wallis (eds.), McGraw-Hill

Hunter, J.S. (1986) "The Exponentially Weighted Moving Average," Journal of Quality Technology, 18, 4, 203-210

Jackson, J.E. (1956) “Quality Control Methods for Two Related Variables”, Industrial Quality Control, 12, 7, 4-8

Jackson, J.E. (1959) "Quality Control Methods for Several Related Variables”, Technometrics, 1, $4,359-377$

Jackson, J.E. (1985) "Multivariate Quality Control”, Communications in Statistics-Theory and Methods, 14, 110, 2657-2688

Jarrett, J.E. and Pan, X. (2006), "The Quality Control Chart for Monitoring Multivariate Auto correlated Processes," Computational Statistics and Data Analysis, 51 , 38621-3870

Jarrett, J.E. and Pan, X. (2007a) "Using Vector Autoregressive Residuals to Monitor Multivariate Processes in the Presence of Serial Correlation," International Journal of Production Economics, 106. 204-216

Jarrett, J.E. and Pan, X (2007b) "Monitoring Variability and Analyzing Multivariate Auto correlated Processes," Journal of Applied Statistics 34 (4) 459-469

Kalagonda, A.A., Kulkarni, S.R. (2003) "Diagnosis of multivariate control chart signal for auto correlated processes," Communications in Statistics-Theory and methods 32 (8): 1665-1684 
Kalagonda, A.A., Kulkarni, S.R. (2004). Multivariate quality control chart for auto correlated processes. Journal of Applied Statistics 31, 3, 317-327

Lee, H.L. and Wang, S (2003) Higher Supply Chain Security with Lower Cost: Lessons from Total Quality Management, Research Paper No. 1824, Stanford Graduate School of Business, Palo Alto, CA

Lowry, C.A.W. Woodall, C.W. Champ and Rigdon, S.E. (1992) "A Multivariate Exponentially Weighted Moving Average Control Chart", Technometrics, vol. 43, 46-53

Lowry, C.A. and Montgomery, D.C. (1995) "A Review of Multivariate Charts, IIE Transactions, $27,800-810$

Lu, C.W., and M.R. Reynolds (1999) "Control Charts for Monitoring the Mean and Variance of Auto correlated Processes”, Journal of Quality Technology 31, 259-274

Maragah, H.O., and Woodall, W.H. (1992) "The Effect of Autocorrelation on the Retrospective X-Chart”, Journal of Statistical Computation and Simulation, 40, 1, 29-42

Mastrangelo, C.M. and Forrest, D.R. (2002) "Multivariate Auto correlated Processes: Data and Shift Generation", Journal of Quality Technology, 34, 2, 216-220

Molnau, W.E., Montgomery, D.C., and Runger, G.C. (2001) "Statistically Constrained Economic Design of the Multivariate Exponentially Weighted Moving Average Control Chart", Quality and Reliability Engineering International, 17, 1, 39-49

Montgomery, D.C. and C.M. Mastrangelo (1991) "Statistical Process Control in a Computer-Integrated Manufacturing Environment", Statistical Process Control in Automated Manufacturing, edited by J.B. Kates and N.F. Hunele, Marcel Dekker, Inc. Series in Quality and Reliability, New York

Montgomery, D.C. (2013) Introduction to Statistical Quality Control, seventh ed., Wiley

Montgomery, D. C. and Friedman, J.J. (1989) "Statistical Process Control in a ComputerIntegrated Manufacturing Environment," Statistical Process Control in Automated Manufacturing, edited by J.B. Kates and N.F. Hunele, Marcel Dekker, Inc. Series in Quality and Reliability, New York

Montgomery, D.C. and Runger, G. C. (2003) Applied Statistics and Probability for Engineers, 3rd ed., Wiley, New York

Montgomery, D.C. and Wadsworth, H.M. (1972) "Some Techniques for Multivariate Quality Control Applications," ASQC Technical Conference Transactions, Washington, DC, May, 427435 
Novak, S. Y. (2011) Extreme Value Methods with Applications to Finance, London: Chapman and Hall/CRC Monographs on Statistics \& Applied Probability

Pan, X. and Jarrett, J. (2004) "Applying State Space into SPC: Monitoring Multivariate Time Series", Journal of Applied Statistics, 31, 4, 397-418

Pan, X. and Jarrett, J.E. (2013) "Using Golden Ratio Search to Improve Paired Construction Quality Controls Charts," International Journal of Economics and Management Engineering (IJEME) 3, 3, 107-111

Papaioannon, A. et al. (2010a) "Application of Multivariate Statistical Methods for Goundwater and Biological Quality Assessment in the context of Public Health," Environ Monit Assess, 170: $1-4,87-97$

Papaioannon, A. et al. (2010b) "Assessment and Modeling of Groundwater Quality Data by Environmentric Methods in the Context of Public Health, Water Resources Management, 24: 12, $3257-3278$

Sonesson, C. and D. Bock (2003) "A Review and Discussion of Prospective Statistical Surveillance in Public Health," Journal of the Royal Statistical Society, Series A, 166, 5-21

Sullivan, J.H. and Woodall, W.H. (1996) A Review of Multivariate Charts, Journal of Quality Technology, 28, 4, 261-264

Testik, M.C. (2005) "Model Inadequacy and Residuals Control Charts for Auto correlated Processes, Quality and Reliability Engineering, 21, 115-130

Tracy, N.D., Young, J.C. and Mason, R.I. (1992) "Multivariate Quality Control Charts for Individual Observations" Journal of Quality Technology, 24, 2, 88-95

Wardell, D.G., Moskowitz, H. and R.D. Plante (1994) "Run-Length Distribution of Special-Cause Control Charts for Correlated Processes", Technometrics, 36

West, D., Delana, S. and Jarrett, J (2002) "Transfer Function Modeling of Processes with Dynamic Inputs", Journal of Quality Technology 34, 3, 315-321

West, D., and Jarrett, J. (2004) "The Impact of First Order Positive Auto regression on Process Control”, International Journal of Business \& Economics, 3, 1, 29-37

Weihs, C and Jessenberger, J. (1999) "Statistische Methoden zur Qualä tssicherung und optimierung, Wiley-VCH, Weinheim

Wierda, S.J. (1994) "Multivariate Statistical Process Control: Recent Results and Directions for Future Researches:, Statistica Neerlandica, 48, 147-168

Wright, C. M., Booth, D. E. and Hu, M. Y. (2001) "Joint Estimation: SPC Method for Short-run Auto correlated Data," Journal of Quality Technology, 33, 3, 365-368 
Woodall, W. H. (2005) "The Use of Control-Charts in Health Care and Public Health Surveillance," Journal of Quality Technology, 38, 2, 89-104

Yang, S.F. and Rahim, R.A. (2005) "Economic Statistical Process Control for Multivariate Quality Characteristics under Weibull shock model", International Journal of Production Economics, 98, 215-226

Yeh, A.B., Hwang, L., Wu, Y. (2004) “A Likelihood-Ration-Based EWMA chart for monitoring variability of multivariate normal processes", IIE Transactions, 36, 865-879

Zhang, C., Yu, H. and Huang, X. (2009) "Quality Control Strategy in Supply Chain under symmetric information," International Journal of Operations Research, 4, 1, 97-116 
Figure 1 (a)

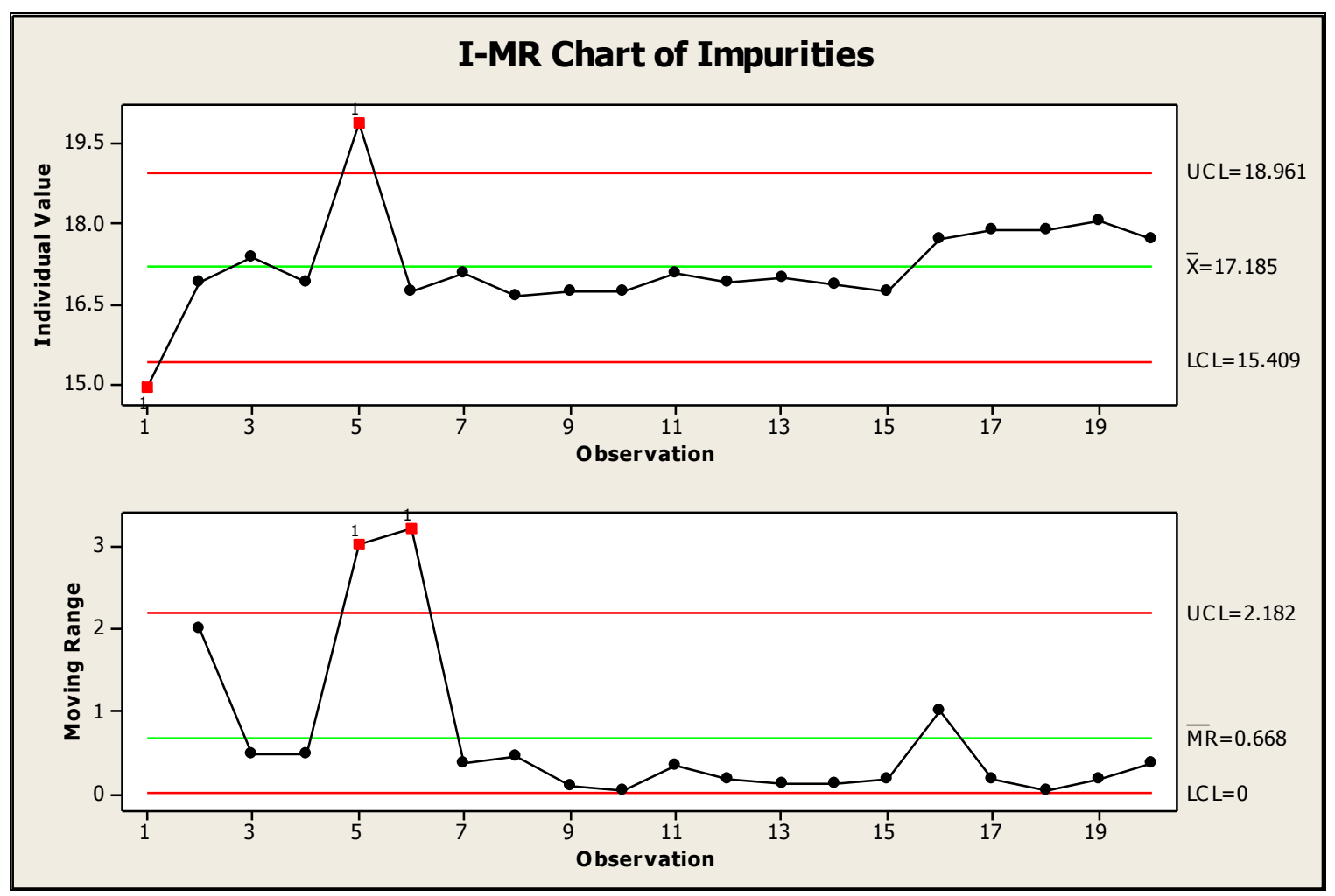

\section{Test Results for I Chart of Impurities}

TEST 1. One point more than 3.00 standard deviations from center line. Test Failed at points: 1, 5

\section{Test Results for MR Chart of Impurities}

TEST 1. One point more than 3.00 standard deviations from center line. Test Failed at points: 5, 6 
Figure 1 (b)

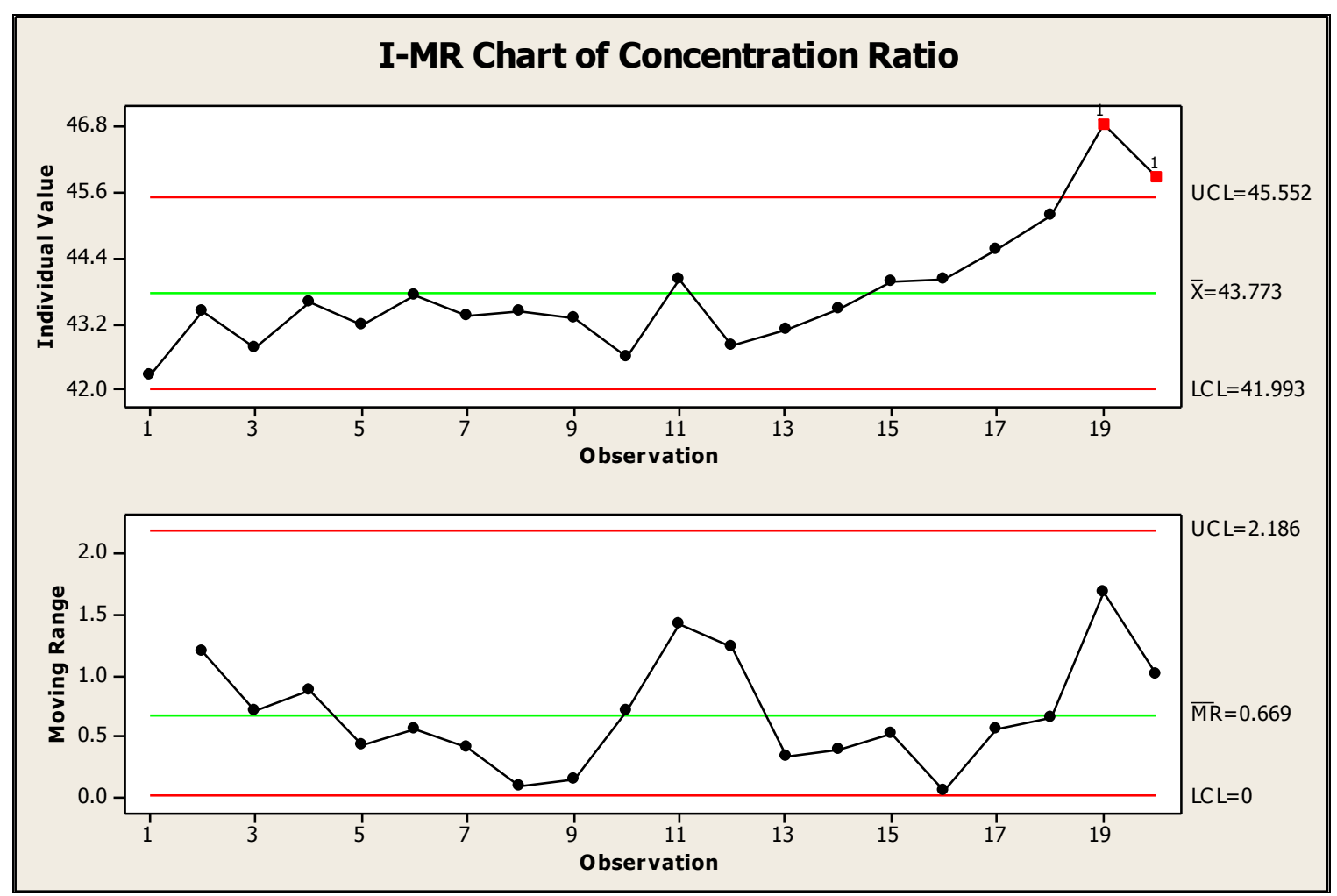

Test Results for I Chart of Conc.

TEST 1. One point more than 3.00 standard deviations from center line. Test Failed at points: 19, 20

No points out of control on MR chart 
Figure 1 (c)

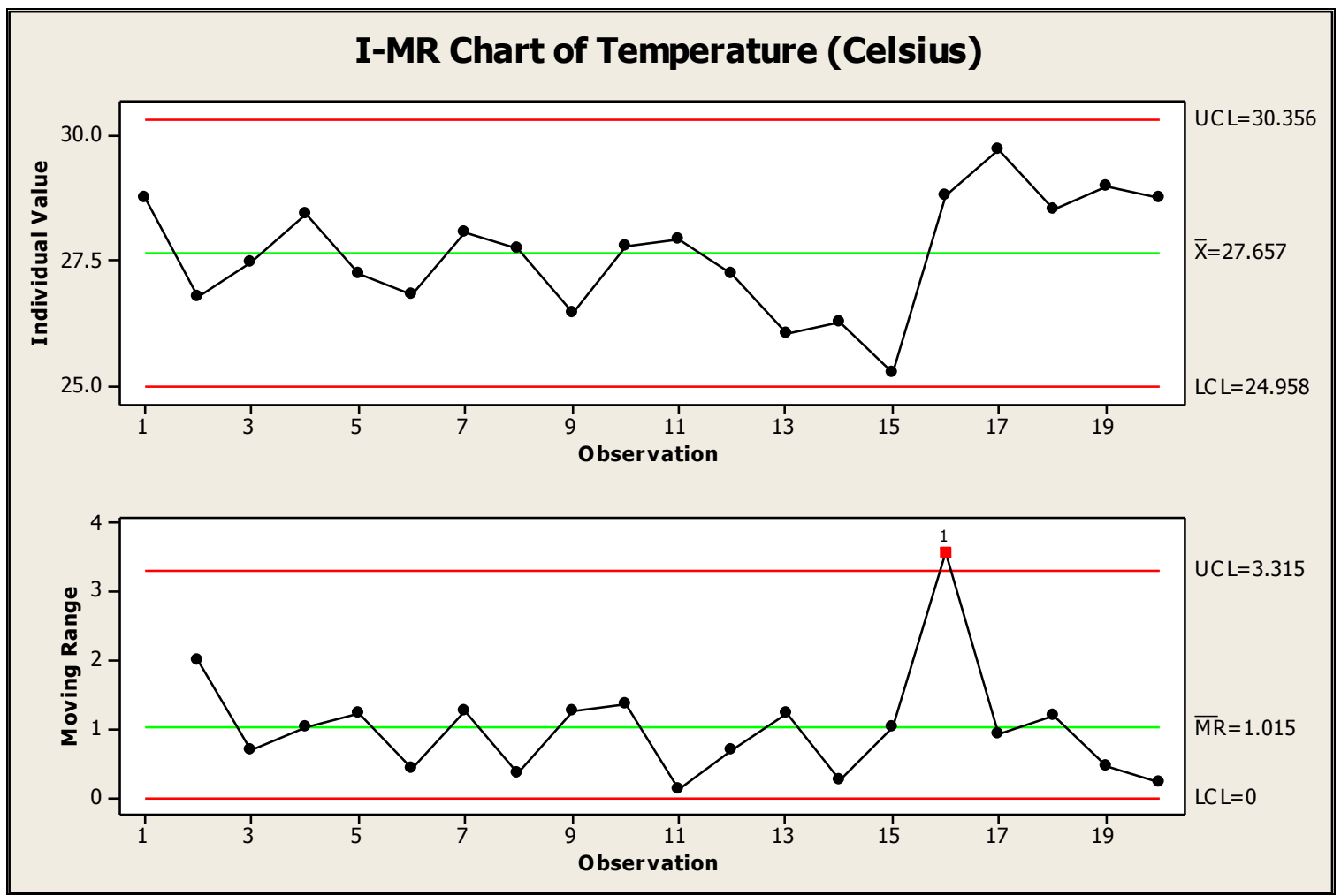

No points out of control on I chart

Test Results for MR Chart of Temp-Celsius

TEST 1. One point more than 3.00 standard deviations from center line.

Test Failed at points: 16 
Figure 2 (a)

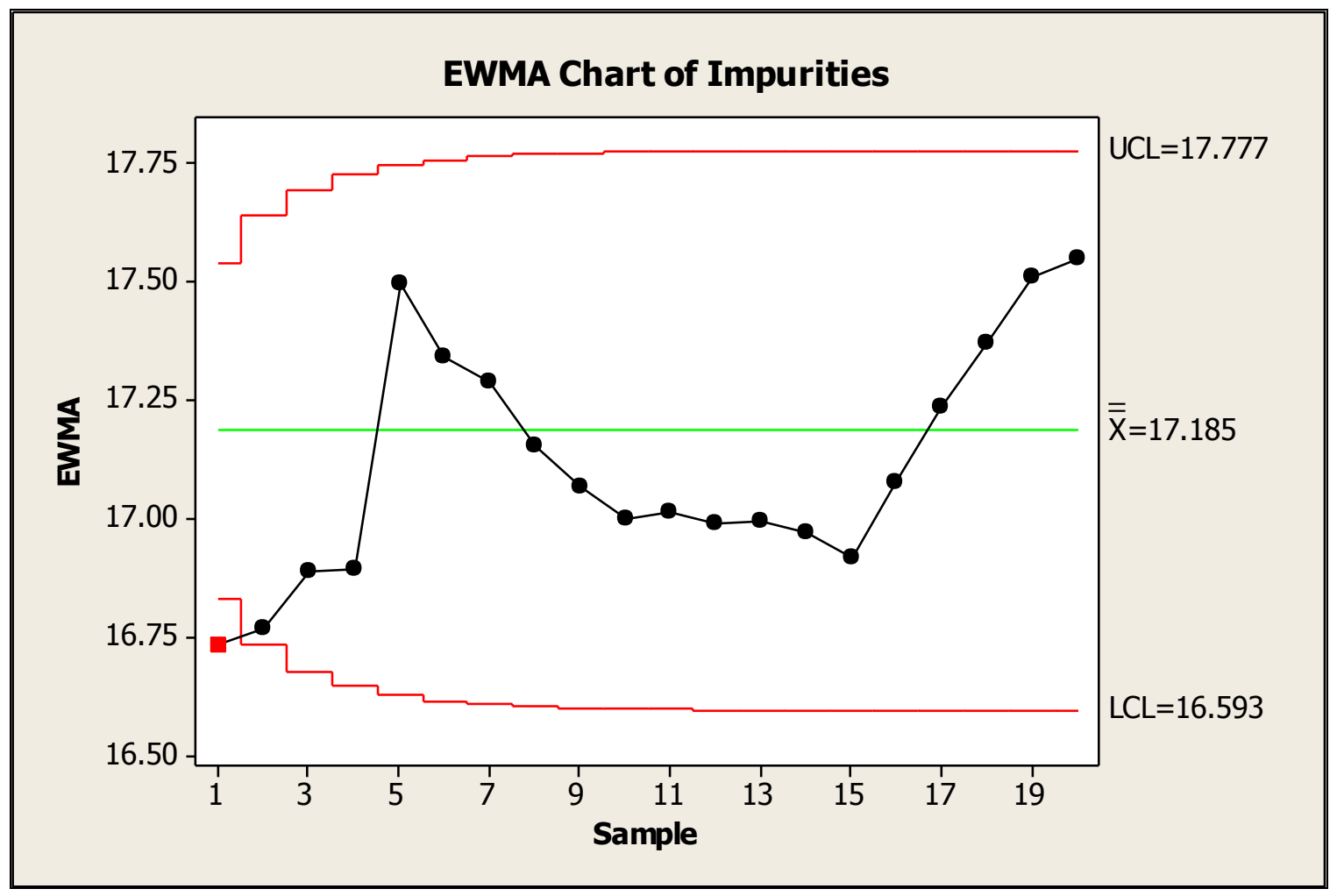

Test Results for EWMA Chart of Impurities

TEST 1. One point more than 3.00 standard deviations from center line. Test Failed at points: 1 
Figure 2 (b)

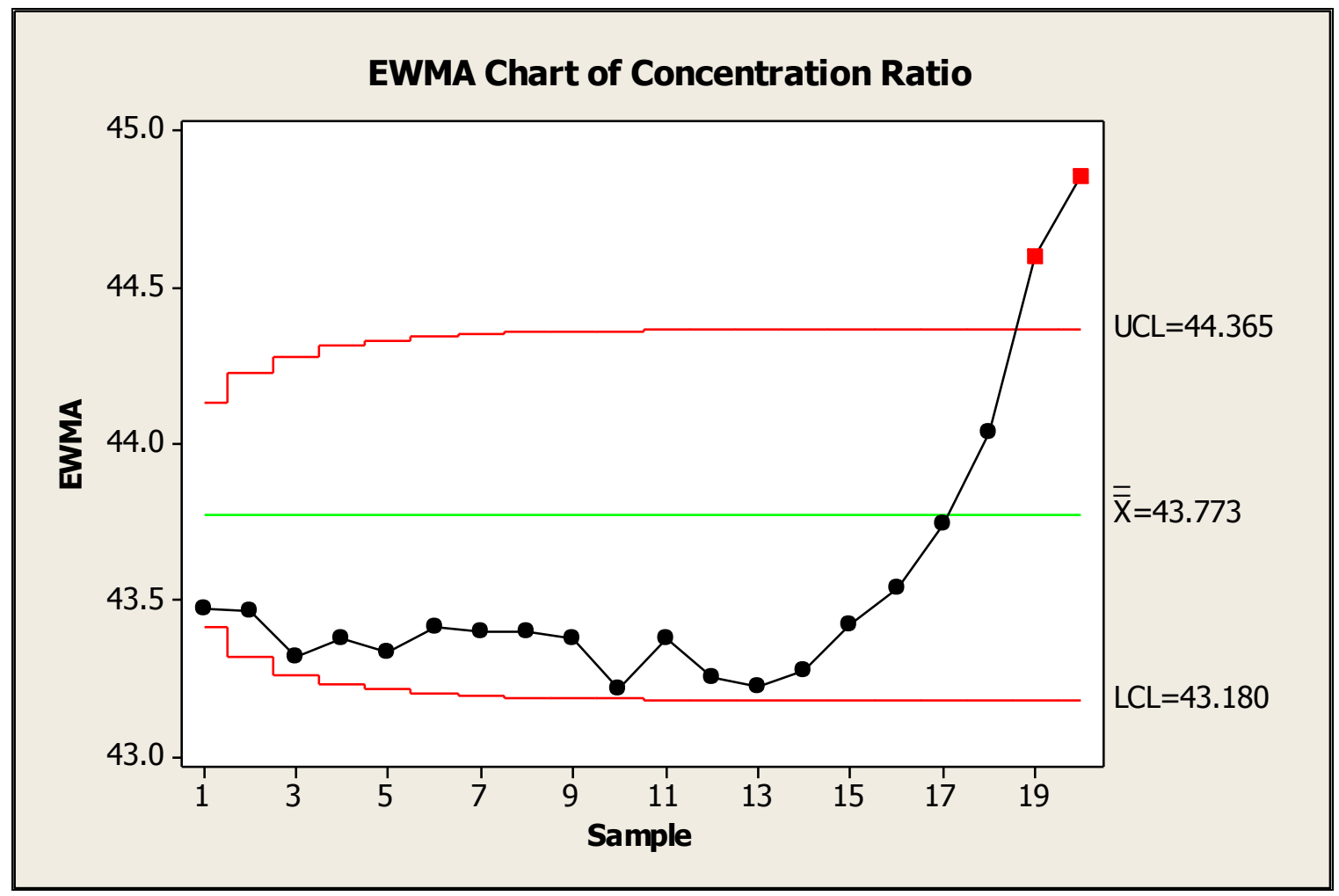

Test Results for EWMA Chart of Conc.

TEST 1. One point more than 3.00 standard deviations from center line. Test Failed at points: 19, 20 
Figure 2 (c)

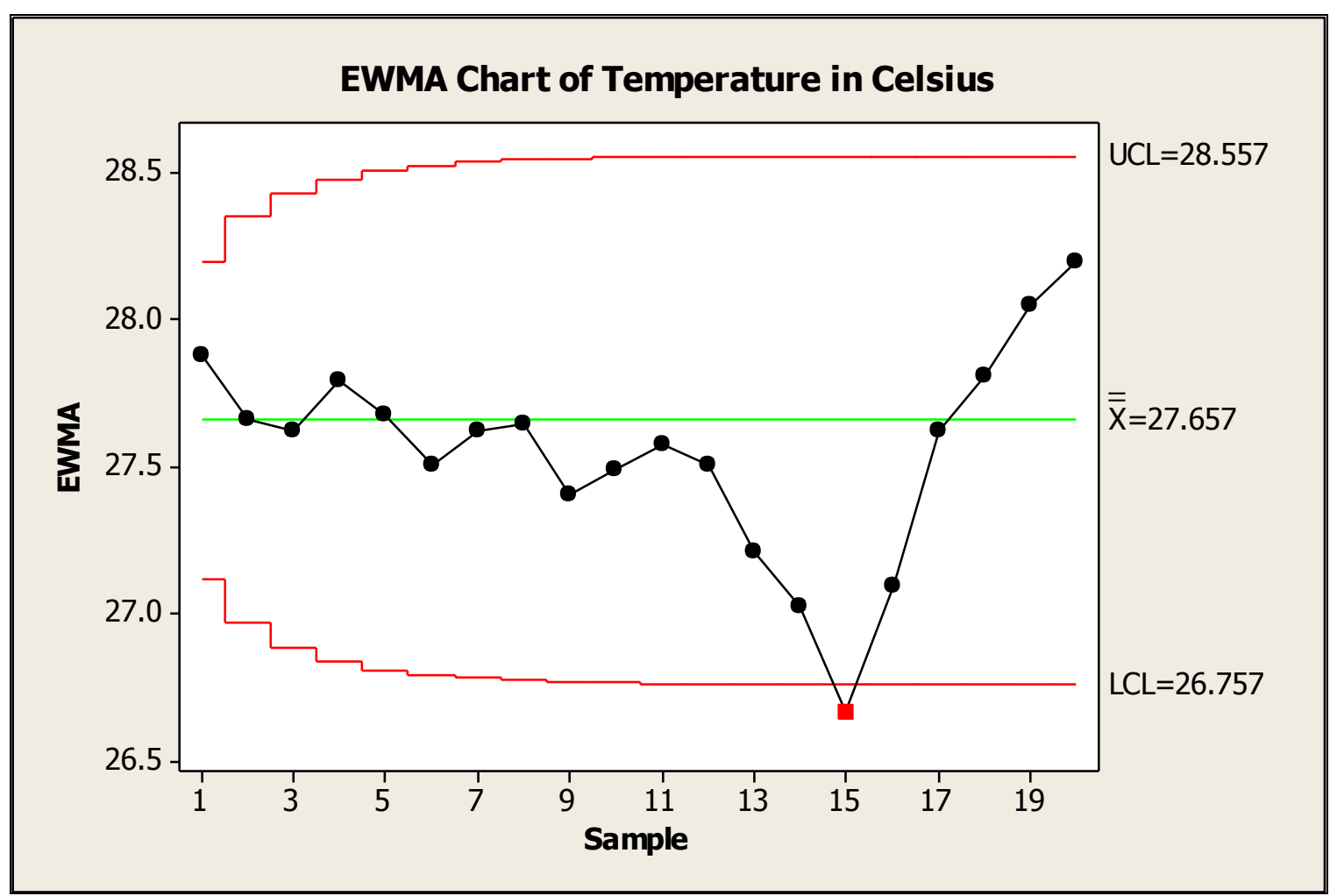

Test Results for EWMA Chart of Temp-Celsius

TEST 1. One point more than 3.00 standard deviations from center line. Test Failed at points: 15 
Figure 3 (a)

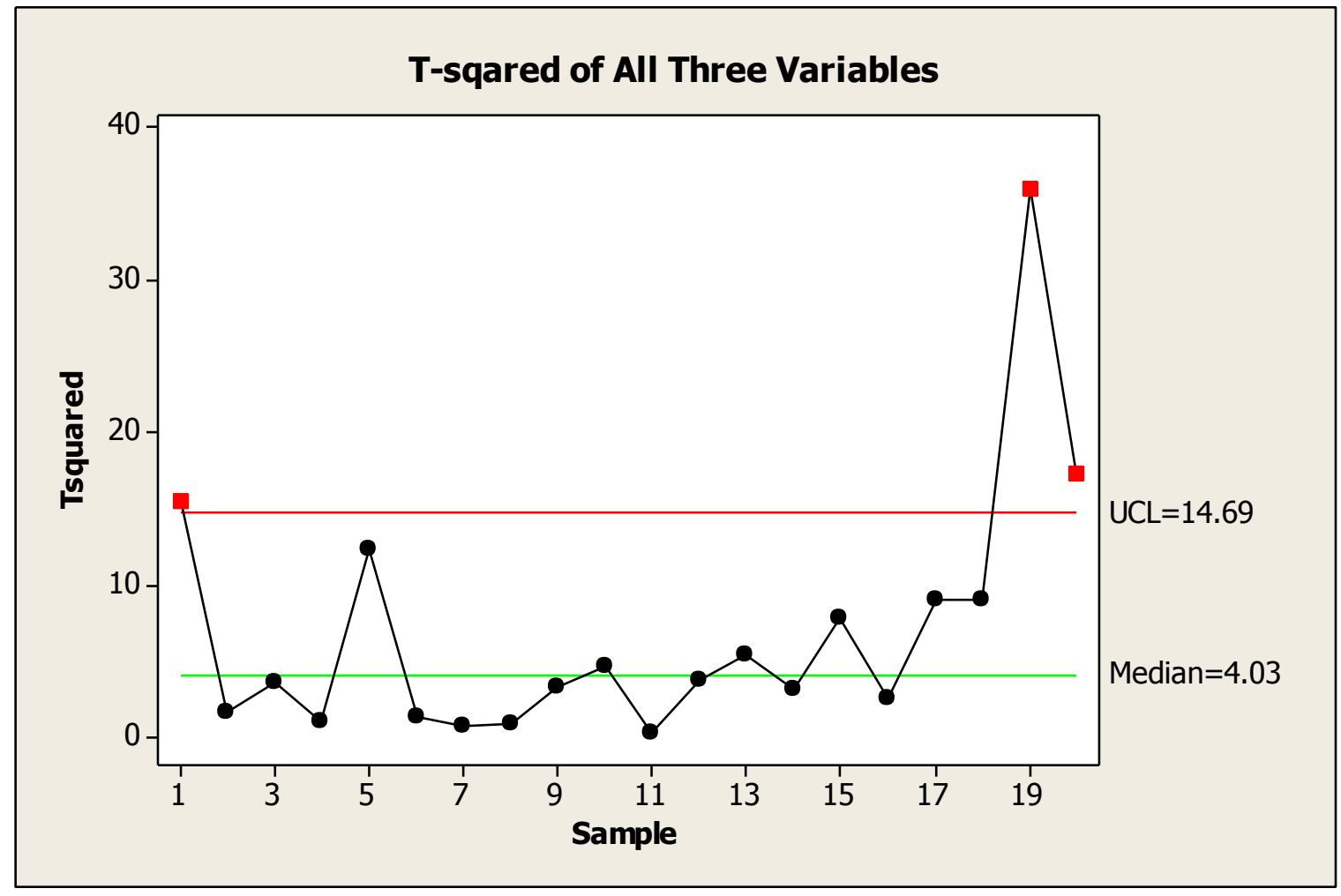

Test Results for Tsquared Chart of Impurities, ..., Conc.

$\begin{array}{cclc}\text { Point } & \text { Variable } & \text { P-Value } \\ \text { Greater Than UCL } & 1 & \text { Impurities } & 0.0021 \\ & & \text { Conc. } & 0.0039 \\ & 19 \text { Temp-Celsius } & 0.0224 \\ & & \text { Conc. } & 0.0000 \\ & 20 \text { Conc. } & 0.0000\end{array}$


Figure 3 (b)

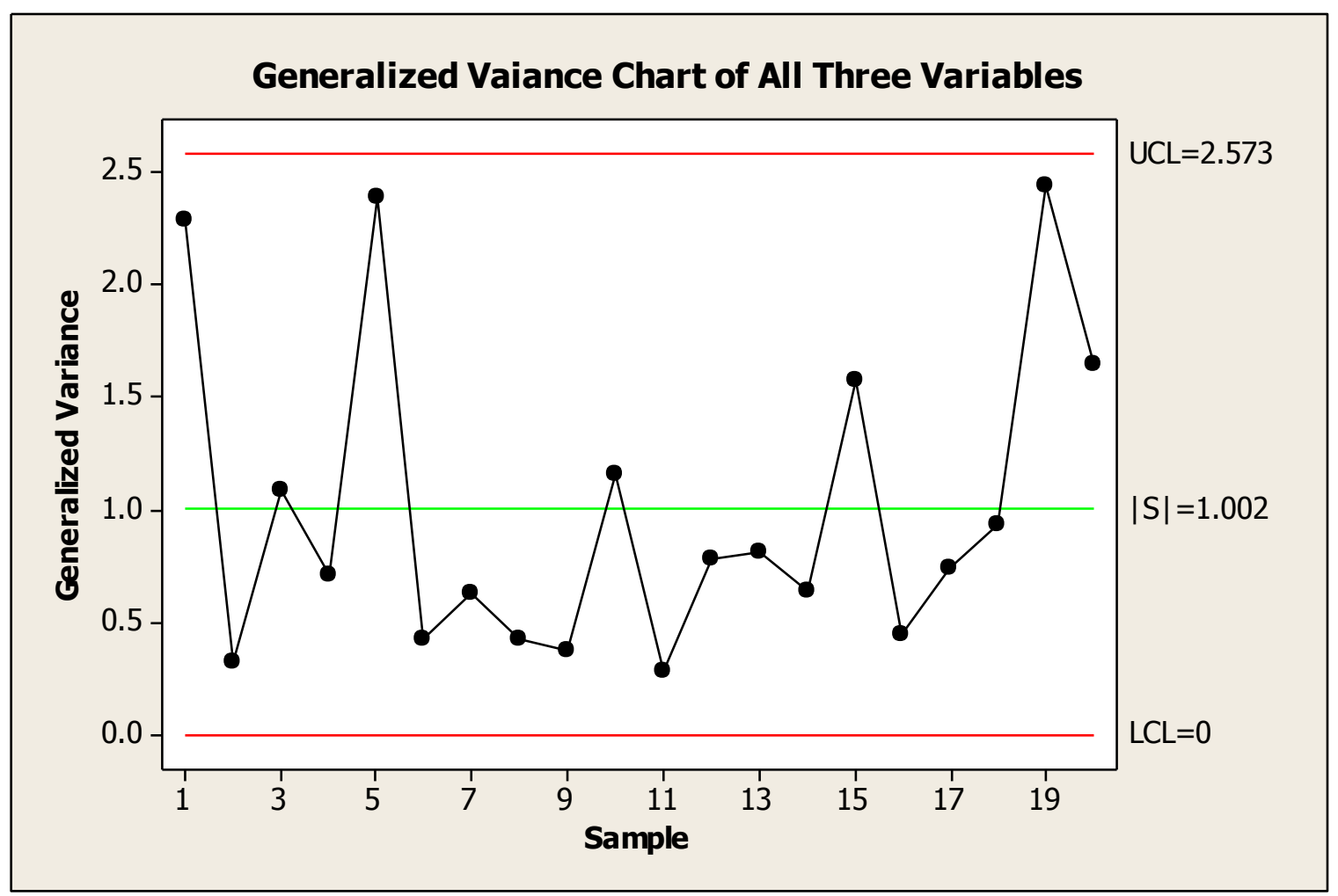

No Points out of Control 